\title{
Analisis Strategi Penanganan Peredaran Narkoba di Rumah Tahanan Negara Kelas II B Banyumas
}

\section{Analysis of Drug Trafficking Management Strategy in Banyumas Class II B State Prison}

\author{
Alfin Azka Fauzi1) \& Arisman²) \\ 1) Program Studi Manajemen Pemasyarakatan, Politeknik Ilmu Pemasyarakatan, Indonesia \\ 2) BPSDM Kementerian Hukum dan HAM, Indonesia
}

Diterima: 05 Mei 2021 Direview: 05 Mei 2021; Disetujui: 06 Agustus 2021

*Coresponding Email:

\section{Abstrak}

Penelitian ini memiliki tujuan yaitu untuk mengetahui bagaimana strategi penanganan terhadap peredaran narkoba di Rumah Tahanan Negara Kelas II B Banyumas. Jenis penelitian yang dilakukan merupakan jenis penelitian kualitatif dan menggunakan metode pengumpulan data kuantitatif yang digunakan untuk melakukan analisis faktor lingkungan dengan metode SWOT, sampel penelitian yaitu 19 petugas dengan penentuan sampel berdasarkan teknik purposive sampling. Hasil penelitian ini menunjukkan bahwa strategi penanganan terhadap peredaran narkoba menunjukkan strategi agresif yang terletak di kuadran I sehingga Rumah Tahanan Negara Kelas II B Banyumas harus bisa memanfaatkan momentum agar dapat menangani terhadap peredaran narkoba dan juga dapat mengendalikan pergerakan narkoba yang ada.

Kata Kunci: Narkoba; Analisis; Strategi; Rumah Tahanan Negara

\begin{abstract}
This study aims to find out how to handle drug trafficking strategy in Banyumas Class II B State Prison. The type of research conducted is a qualitative type of research and uses quantitative data collection method used to analyze environmental factors with SWOT method, research sample is 19 officers with sample determination based on purposive sampling technique. The results of this study showed that the strategy of handling drug trafficking shows an aggressive strategy located in quadrant I so that banyumas Class II B State Prison should be able to utilize momentum in order to handle drug trafficking and also be able to control the movement of existing drugs.
\end{abstract}

Keywords: Drugs; Analysis; Strategy; State prison

How to Cite: Fauzi, A.A. \& Arisman (2021). Analisis Strategi Penanganan Peredaran Narkoba di Rumah Tahanan Negara Kelas II B Banyumas. Journal of Education, Humaniora and Social Sciences (JEHSS). 4 (2): 642-649. 


\section{PENDAHULUAN}

Peredaran narkoba saat ini di Lembaga Pemasyarakatan dan Rumah Tahanan Negara tetap marak meskipun pelaksanaan hukuman mati telah dilaksanakan terhadap beberapa terpidana mati pengedar narkotika. Presiden Joko Widodo menyatakan bahwa Indonesia sudah sampai ke tahap darurat narkoba sehingga Presiden tidak akan mengabulkan grasi yang diajukan terpidana pengedar narkoba. Selain itu, berdasarkan statistik peredaran narkoba di Indonesia telah terdapat 4,5 juta orang yang terkena narkoba dan ada 1,2 juta orang yang sudah tidak bisa direhabilitasi karena kondisinya dinilai terlalu parah.

Penyalahgunaan narkotika dan psikotropika merupakan persoalan yang cukup kompleks yaitu mulai dari proses hukum hingga proses pemulihan korban. Persoalan hukum karena terkait dengan Undang Undang Nomor 5 Tahun 1997 tentang Psikotropika dan Undang-Undang Nomor 35 Tahun 2009 tentang Narkotika. Di satu sisi pelanggaran terhadap kedua undang-undang tersebut merupakan tindak pidana dan disisi lain korban ketergantungan terhadap narkotika wajib menjalani pengobatan dan perawatan (rehabilitasi). Salah satu upaya Lembaga Pemasyarakatan atau Rumah tahanan dalam penanggulangan penyalahgunaan Narkotika oleh Narapidana dapat juga dilakukan dengan menjalankan kebijakan rehabilitasi sebagaimana yang diatur dalam Pasal 54 Undang-Undang Nomor 35 Tahun 2009 tentang Narkotika bahwa pecandu Narkotika dan korban penyalahgunaan Narkotika wajib menjalani rehabilitasi medis dan rehabilitasi sosial.

Seperti halnya yang dilakukan Rumah Tahanan Negara Kelas II B Banyumas dimana Warga Binaan secara rutin diikutsertakan pada program rehabilitasi sosial narkoba, menurut Karutan, Program Rehabilitasi tersebut bertujuan agar para warga binaan benarbenar siap untuk tidak mengulangi perbuatannya dan kegiatan ini merupakan wujud implementasi dari revitalisasi keamanan untuk para narapidana. Akan tetapi pelaksanaan rehabilitasi belum dilaksanakan secara merata baik oleh Lembaga Pemasyarakatan maupun Rumah Tahanan. Berdasarkan Undang-Undang Nomor 12 Tahun 1995 tentang Pemasyarakatan juga terlihat bahwa dengan adanya lapas narkotika yang disediakan khusus bagi pelanggar hukum kejahatan narkotika atau narkoba. Namun Lembaga Pemasyarakata Narkotika belum menyeluruh tersedia di seluruh wilayah Indonesia. Tentunya Lapas umum menjadi harapan dan tempat sementara bagi orang yang tersangkut kasus narkotika.

Upaya Lembaga Pemasyarakatan atau Rumah Tahanan dalam penanggulangan penyalahgunaan narkotika oleh Narapidana atau Tahanan dapat dilakukan dengan menjalankan instrumen hukum Peraturan Menteri Hukum dan HAM Nomor 6 Tahun 2013 tentang Tata Tertib Lembaga Pemasyarakatan dan Rumah Tahanan Negara secara tegas, sebab dalam dalam Pasal 4 huruf g mengatur bahwa, "Narapidana dilarang menyimpan, membuat, membawa, mengedarkan, dan/atau mengkonsumsi narkotika dan/atau prekursor narkotika serta obat-obatan lain yang berbahaya dan pada Pasal 10 ayat (3) mengkategorikan larangan dalam Pasal 4 huruf g tersebut dapat diancam dengan hukuman disiplin tingkat berat".

Berdasarkan data penggeledahan Rumah Tahanan Negara Kelas II B Banyumas, terlihat bahwa dalam hitungan tahun terdapat adanya narkoba jenis sabu dan narkoba jenis lainnya, dan data penggeledahan blok WBP menunjukan, bahwa petugas mendapati alat hisap yang digunakan oleh WBP selain itu petugas juga menemukan sajam dan benda lainnya yang terlarang yang berada di blok kamar hunian WBP. Hal ini menunjukan bahwa lingkungan Rumah Tahanan Negara Kelas II B banyumas merupakan lingkungan yang 
rawan akan peredaran narkoba, dan perlu adanya deteksi dini dan strategi untuk dapat mengetahui pergerakan narkoba, baik secara internal maupun eksternal.

Penyalahgunaan Narkotika di Lembaga Pemasyarakatan atau Rumah Tahanan bisa terjadi kapan saja dan pergerakan narkoba yang ada di dalam Lapas maupun Rutan terus bergerak. Banyak faktor yang menyebabkan narapidana masih melakukan penyalahgunaan narkotika di dalam Lapas atau Rutan yaitu karena narkoba masih bisa didapat di Lembaga Pemasyarakatan atau masih ada permintaan dari dalam. Karena pada dasarnya narapidana yang berada di dalam masih dalam tahap rehabilitasi dan belum sepenuhnya untuk dapat lepas dari konsumsi narkoba. Apabila pergerakan narkoba di balik jeruji tidak terpantau, maka yang akan terjadi adalah perederan yang akan meluas didalam Lapas maupun Rutan.

\section{METODE PENELITIAN}

Penelitian ini merupakan jenis penelitian kualitatif. Dimana penelitian ini ingin mengetahui studi secara empiris mengenai fenomena atau persoalan mendalam yang ada di lapangan. Di samping itu, peneliti perlu terjun langsung ke lapangan sehingga jenis penelitian kualitatif lebih tepat untuk dapat mendeskripsikan keadaan dilapangan.

Sumber data dalam penelitian ini yaitu: (a) Data Primer, Sumber data primer merupakan sumber data objektif yang diperoleh secara langsung dari hasil, wawancara dan pembagian kuesioner kepada petugas. (b) Data Sekunder, Sumber data sekunder merupakan data yang dikumpulkan oleh peneliti yang bersumber dari studi kepustakaan, referensi sumber bacaan ataupun peraturan perundang undangan yang berkaitan dengan penelitian.

Metode pengumpulan data dalam penelitian ini yaitu dengan melalui: (a) Wawancara, peneliti melakukan pengumpulan data dengan wawancara kepada 2 pegawai yang menjadi key informan dalam penelitian ini yaitu kepala kesatuan pengamanan Rutan (KPR) dan kepala regu pengamanan (Karupam). (b) Kuisioner, peneliti menggunakan kuisioner yang disebarkan kepada responden, dalam hal ini sampel penelitian berjumlah 19 pegawai untuk dapat mengumpulkan data yang berbentuk pendapat mengenai bobot analisis yang menjadi fokus dalam penelitian ini, dengan penentuan sampel berdasarkan teknik purposive sampling. (c) Observasi, peneliti secara langsung dapat mengamati gambaran apa adanya di lapangan. Data yang ingin peneliti dapatkan dengan metode ini adalah deskripsi umum tentang subjek penelitian, yang selanjutnya difokuskan untuk menjadi objek penelitian. (d) Studi Pustaka, adapun kumpulan data tersebut berasal dari referensi sumber bacaan maupun peraturan perundangan yang berkaitan dengan penelitian ini, kemudian digunakan sebagai referensi maupun masukan kepada peneliti yang dijadikan sebagai data pendukung dalam memperkuat data primer.

\section{HASIL DAN PEMBAHASAN}

\section{Analisis Faktor Strategis Lingkungan Internal}

Analisis Faktor Strategis Lingkungan Internal berfungsi untuk mengetahui faktor strategis yang ada di lingkungan internal Rumah Tahanan Negara Kelas II B Banyumas. Analisis faktor kekuatan sangat penting dilakukan guna untuk melihat seberapa besar potensi kekuatan yang dimiliki oleh lingkungan internal Rumah Tahanan dalam upaya penanganan peredaran narkoba. Kemudian Analisis faktor kelemahan merupakan faktor yang harus dipetakan dan benar benar di perhatikan oleh lingkungan internal Rumah Tahanan dalam upaya penanganan peredaran narkoba. Adapun analisis terhadap kekuatan dan kelemahan di lingkungan internal sebagai berikut: 
Vol 4, No. 2, November 2021: 642-649

Tabel 1. Tabel Faktor Lingkungan Internal

\begin{tabular}{|c|c|c|c|c|c|c|c|}
\hline & No & Faktor Strategis & $\begin{array}{l}\text { Tingkat } \\
\text { Signifikan }\end{array}$ & Bobot & Rating & Skor & \\
\hline \multirow[b]{5}{*}{$\begin{array}{l}\underset{\pi}{\pi} \\
\frac{\pi}{2} \\
\frac{1}{0} \\
\\
\end{array}$} & 1 & $\begin{array}{lc}\text { Adanya } & \text { SOP } \\
\text { penggledahan barang }\end{array}$ & 69 & 0,13 & 3,63 & 0,471 & $\begin{array}{l}\text { Jumlah } \\
\text { Kekuatan }\end{array}$ \\
\hline & 2 & $\begin{array}{l}\text { Rutan memiliki alat } \\
\text { detector }\end{array}$ & 70 & 0,13 & 3,68 & 0,478 & 2,378 \\
\hline & 3 & $\begin{array}{l}\text { Petugas } \\
\text { melaksanakan Sidak } \\
\text { secara rutin di blok } \\
\text { WBP atau Tahanan }\end{array}$ & 71 & 0,13 & 3,73 & 0,484 & \\
\hline & 4 & $\begin{array}{lr}\text { Pengawasan } & \text { di } \\
\text { lingkungan } & \text { Rutan } \\
\text { berbasis CCTV } & \\
\end{array}$ & 72 & 0,14 & 3,78 & 0,529 & \\
\hline & 5 & $\begin{array}{l}\text { Lokasi Rutan dekat } \\
\text { dengan lingkungan } \\
\text { TNI/POLRI }\end{array}$ & 66 & 0,12 & 3,47 & 0,416 & \\
\hline \multirow{6}{*}{ 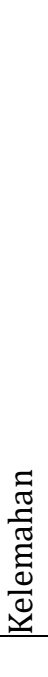 } & 1 & $\begin{array}{l}\text { Adanya over capacity } \\
\text { di Rutan }\end{array}$ & 28 & 0,05 & 1,47 & 0,073 & $\begin{array}{l}\text { Jumlah } \\
\text { Kelemahan }\end{array}$ \\
\hline & 2 & $\begin{array}{ll}\text { Integritas } & \text { petugas } \\
\text { yang rendah } & \end{array}$ & 21 & 0,04 & 1,1 & 0,044 & 0,552 \\
\hline & 3 & $\begin{array}{l}\text { Jumlah petugas di } \\
\text { Rutan tidak sebanding } \\
\text { dengan jumlah } \\
\text { Penghuni. }\end{array}$ & 27 & 0,05 & 1,42 & 0,071 & \\
\hline & 4 & $\begin{array}{l}\text { Pengawasan yang } \\
\text { kurang dari petugas }\end{array}$ & 44 & 0,08 & 2,31 & 0,184 & \\
\hline & 5 & $\begin{array}{l}\text { Tidak } \\
\text { dilaksanakannya } \\
\text { program rehabilitasi } \\
\text { di dalam Rutan }\end{array}$ & 43 & 0,08 & 2,26 & 0,18 & \\
\hline & & Jumlah & 969 & 1,00 & & & \\
\hline
\end{tabular}

Sumber data : Olahan Penulis

Nilai Faktor Strategis Lingkungan Internal
$=$ Kekuatan - Kelemahan
$=2,378-0,552$
$=1,826$

Berdasarkan tabel faktor lingkungan internal menghasilkan nilai kekuatan pihak Rutan sebesar 2,378 dan nilai kelemahan sebesar 0,552 dari masing masing jumlah kekuatan dan kelemahan yang ada, untuk mencari nilai faktor strategis lingkungan internal yaitu dengan mengurangkan nilai kekuatan terhadap kelemahan dan dihasilkan nilai 1,826. Dengan demikian kondisi Rutan sedang dalam kondisi yang kuat dan mampu untuk dapat menangani peredaran narkoba.

\section{Analisis Faktor Strategis Lingkungan Eksternal}

Faktor Strategis Lingkungan Eksternal merupakan faktor yang memiliki potensi untuk dapat dikembangkan maupun segala ancaman yang ada di lingkungan eksternal Rumah Tahanan. Peluang merupakan faktor pendukung yang dapat berdampak positif apabila dilakukan tindakan yang tepat dan memaksimalkan lingkungan strategis yang ada. Ancaman. Ancaman merupakan faktor yang dapat berdampak negatif dan dapat 
Alfin Azka Fauzi \& Arisman, Analisis Strategi Penanganan Peredaran Narkoba di Rumah Tahanan Negara Kelas II B Banyumas

menghambat segala proses yang ada. Pentingnya mengenali dan memahami ancaman agar dapat mengantisipasi adanya hal hal yang bersifat merugikan bagi organisasi ke depan. Adapun analisis terhadap peluang dan ancaman di lingkungan eksternal sebagai berikut:

Tabel 2. Tabel Faktor Lingkungan Eksternal

\begin{tabular}{|c|c|c|c|c|c|c|c|}
\hline & No & Faktor Strategis & $\begin{array}{l}\text { Tingkat } \\
\text { Signifikan }\end{array}$ & Bobot & Rating & Skor & \\
\hline \multirow[b]{5}{*}{ 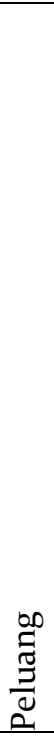 } & 1 & $\begin{array}{l}\text { Adanya kordinasi } \\
\text { yang baik dengan } \\
\text { BNN/POLRI }\end{array}$ & 69 & 0,13 & 3,63 & 0,471 & $\begin{array}{l}\text { Jumlah } \\
\text { Peluang }\end{array}$ \\
\hline & 2 & $\begin{array}{l}\text { Pelaksanaan } \\
\text { penggledahan } \\
\text { blok terintegrasi }\end{array}$ & 63 & 0,13 & 3,31 & 0,430 & 2,225 \\
\hline & 3 & $\begin{array}{l}\text { Pelaksanaan } \\
\text { monitoring } \\
\text { Kakanwil secara } \\
\text { rutin }\end{array}$ & 70 & 0,15 & 3,68 & $0,55^{2}$ & \\
\hline & 4 & $\begin{array}{l}\text { Adanya } \\
\text { Pengawas } \\
\text { Eksternal Rutan }\end{array}$ & 61 & 0,13 & 3,21 & 0,417 & \\
\hline & 5 & $\begin{array}{l}\text { Layanan } \\
\text { pengaduan dari } \\
\text { masyarakat } \\
\text { sekitar Rutan } \\
\end{array}$ & 56 & 0,12 & 2,94 & 0,352 & \\
\hline \multirow{4}{*}{ 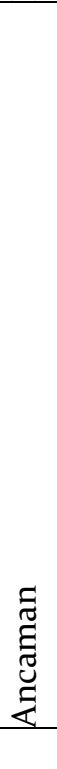 } & 1 & $\begin{array}{l}\text { Adanya } \\
\text { pepohonan besar } \\
\text { disekitar } \\
\text { Eksternal Rutan }\end{array}$ & 66 & 0,14 & 3,47 & 0,485 & $\begin{array}{l}\text { Jumlah } \\
\text { Ancaman }\end{array}$ \\
\hline & 2 & $\begin{array}{l}\text { Adanya narkoba } \\
\text { di dalam Rutan } \\
\text { dikarenakan } \\
\text { komunikasi } \\
\text { dengan pengedar } \\
\text { diluar Rutan }\end{array}$ & 38 & o,o8 & 2 & 0,16 & 0,773 \\
\hline & 3 & $\begin{array}{l}\text { Adanya narkoba } \\
\text { di dalam Rutan } \\
\text { dikarenakan } \\
\text { penambahan } \\
\text { yang berasal dari } \\
\text { teman pergaulan } \\
\text { narkoba }\end{array}$ & 35 & 0,07 & 1,84 & 0,128 & \\
\hline & & Jumlah & 458 & 1,00 & & & \\
\hline
\end{tabular}

Sumber data : Olahan Penulis

$$
\begin{gathered}
\text { Nilai Faktor Strategis Lingkungan Eksternal } \\
=\text { Peluang }- \text { Ancaman } \\
=\mathbf{2 , 2 2 5}-\mathbf{0 , 7 7 3} \\
=\mathbf{1 , 4 5 2}
\end{gathered}
$$

Berdasarkan tabel faktor lingkungan eksternal menghasilkan nilai peluang pihak Rutan sebesar 2,225 dan nilai ancaman sebesar 0,773 ,dari masing masing jumlah nilai peluang dan ancaman yang ada, untuk mencari nilai faktor strategis lingkungan eksternal yaitu dengan mengurangkan nilai peluang terhadap ancaman dan dihasilkan nilai 1,452. Dengan demikian Rutan memiliki peluang yang besar untuk dapat menangani peredaran narkoba. 
Untuk dapat mengetahui posisi Rutan dalam menangani peredaran narkoba dapat digambarkan dengan diagram matriks SWOT, dibawah ini diagram matriks SWOT:

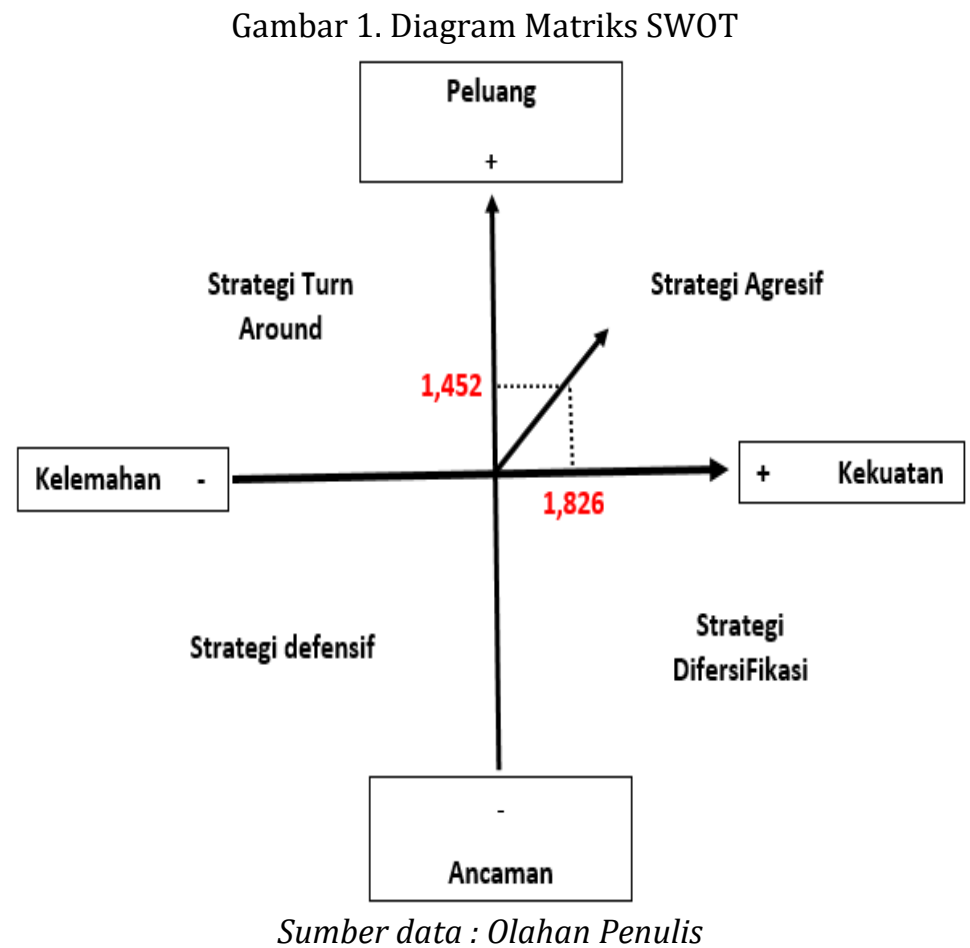

Berdasarkan hasil perhitungan analisis faktor lingkungan internal dan faktor lingkungan eksternal berada pada kuadran I yaitu strategi agresif. Nilai yang diperoleh dari analisis faktor lingkungan internal yaitu 1,826 yang terletak pada sumbu absis bernilai positif. Nilai yang diperoleh dari analisis factor lingkungan eksternal yaitu 1,452 yang terletak pada sumbu ordinat bernilai positif.

Pengembangan analisis SWOT secara kuantatif melalui perhitungan Analisis SWOT yang dikembangkan oleh Pearce dan Robinson (1998) agar diketahui secara pasti posisi organisasi yang sesungguhnya. Posisi strategi penanganan terhadap narkoba berada pada kuadran I, sehingga Rumah Tahanan Negara Kelas II B Banyumas memiliki strategi yang tepat yang kemudian menjadi momentum untuk dapat menangani peredaran narkoba. Strategi tersebut dapat dijelaskan sebagai berikut :

1. Mengefektifkan kegiatan penggledahan terintegrasi bersama BNN dan POLRI secara rutin dan tersistematis. Penggeledahan dan sidak ke dalam blok merupakan salah satu strategi dalam proses penanganan narkoba didalam Rutan. Untuk dapat memaksimalkan dalam proses penggeledahan dan sidak ke dalam blok yaitu dengan menjalin kordinasi dengan pihak pihak yang menjadi mitra Rutan seperti POLRI ataupun BNN. Dengan menjalin kordinasi dengan pihak pihak terkait diharapkan untuk dapat memaksimalkan kegiatan penggeledahan dan pemeriksaan blok WBP atau Tahanan. Hal ini sejalan dengan pernyataan dari Kepala Kesatuan Pengamanan Rutan, beliau menyampaikan bahwa:

2. "Selama ini kita berkordinasi dengan Kepolisian ya untuk penggeledahan dan sidak sidak kamar dan setiap sidak itu ada saja yang didapatkan barang barang terlarangnya, seperti sajam ataupun benda yang lain".

3. Memaksimalkan pemeriksaan barang yang masuk dan pemeriksaan badan bagi pengunjung ke dalam Rutan dengan alat detector yang ada. Pemeriksaan barang 
barang yang masuk kedalam Rutan menjadi hal yang wajib sesuai dengan SOP yang ada. Memaksimalkan fungsi alat detector yang ada menjadi solusi untuk dapat mempermudah pelaksanaan pemeriksaan barang. Apabila ada barang mencurigakan seperti narkoba di dalam makanan atau barang yang akan di berikan kepada WBP ataupun Tahanan di Rutan, maka alat detector akan memunculkan instrument terhadap barang yang dianggap terlarang. Hal ini sejalan dengan pernyataan dari kepala regu pengamanan, beliau menyampaikan bahwa:

4. "Di Rutan Banyumas ini memang untuk saran prasarana yang digunakan dalam proses pemeriksaan barang masih terbatas, seperti metal detector, akan tetapi biasanya kita sebagai petugas selalu memeriksa baik dengan metal detector maupun dengan manual pengecekan".

5. Memperketat pengawasan dari petugas kepada WBP atau Tahanan dan Memaksimalkan fungsi CCTV di sekitar lingkungan Rutan. Pengawasan menjadi suatu hal yang penting, baik pengawasan secara langsung maupun tidak langsung yaitu terpantau dengan menggunakan CCTV. Apabila pengawasan di dalam Rutan diperketat dengan menggunakan CCTV maka pelaksanaan fungsi pengawasan akan meningkat dan akan berdampak positif bagi pelaksanaan penanganan narkoba. Hal ini sejalan dengan hasil observasi peneliti yaitu di Rutan Banyumas masih adanya CCTV yang rusak dan tidak berfungsi, letak CCTV tersebut merupakan tempat yang memang kurang pengawasan dari petugas, maka dari itu pentingnya Rutan untuk bisa memperbaiki dan memaksimalkan sarana prasarana yang ada, guna mendukung dalam proses pengawasan terhadap WBP maupun Tahanan.

6. Meningkatkan integritas sumber daya lingkungan yang ada baik petugas maupun WB. Integritas petugas menjadi ujung tombak dalam penanaganan masalah narkoba ini, petugas harus bekerja sesuai dengan SOP yang ada tanpa adanya pelanggaran kode etik petugas yang berkaitan dengan peredaran narkoba di dalam Lapas maupun Rutan. Banyak kasus peredaran narkoba dikarenakan integritas petugas yang rendah. WBP ataupun Tahanan juga perlu diberikan sosialisasi terkait dengan program Rutan dalam menangani peredaran narkoba.

7. Penguatan program rehabilitasi khsusnya bagi WBP secara berkala. Program rehabilisasi yang dilaksanakan di Rumah Tahanan Negara Kelas II B Banyumas merupakan program yang sudah berjalan dengan baik. Berdasarkan hasil pengamatan peneliti, Rutan Banyumas sudah memiliki MOU dan kerjasama yang baik dengan BNN, terbukti dengan dilaksanakannya kegiatan penggeledahan dan juga tes urin secara berkala serta dalam kegiatan rehabilitasi sudah berjalan dengan baik. Akan tetapi masih perlunya penguatan dalam segi strategi program rehabilitasi untuk dapat memaksimalkan program rehabilitasi.

\section{SIMPULAN}

Berdasarkan analisis SWOT mengenai faktor lingkungan diatas, dapat disimpulkan bahwa Rumah Tahanan Negara Kelas II B Banyumas memiliki kekuatan dan peluang yang lebar untuk dapat menangani peredaran narkoba, hal itu dikarenakan posisi Rumah Tahanan Negara Kelas II B Banyumas terletak pada kuadran I, dimana dalam kuadran ini yang dapat diambil adalah strategi agresif. Strategi agresif yang dimiliki berangkat dari kekuatan Rutan yang berasal dari internal Rutan dan kemudian memiliki peluang yang berasal dari eksternal Rutan. Dengan demikian Rutan harus bisa memaksimalkan momentum dalam kondisi yang mendukung untuk dapat menangani adanya peredaran narkoba di lingkungan Rumah Tahanan Negara kelas II B Banyumas. 


\section{DAFTAR PUSTAKA}

Affifah, M. N., Wahyudi, S., \& Hendriana, R. (2018). Pembinaan Narapidana Perempuan Pelaku Tindak Pidana Korupsi Di Lembaga Pemasyarakatan Perempuan Kelas Iia Bandung. SLR, 237-248.

Aldo (2020). Peran Kesatuan Pengamanan Lapas Dalam Upaya Pencegahan Penyelundupan Narkotika Di Lembaga Pemasyarakatan. Justitia : Jurnal Ilmu Hukum dan Humaniora, Hal 420-433.

Asrul (2020). Efektivitas Tugas Dan Fungsi Petugas Lembaga Pemasyarakatan Terhadap Pencegahaan Peredaran Narkotika. Alauddin Law Development (ALDEV) : Jurusan Ilmu Hukum, Fakultas Syariah dan Hukum, Vol 2 No 3.

Arafat, Muhammad (2020) Upaya Direktorat Reserse Narkoba Kepolisian Daerah Sumatera Selatan Dalam Penanggulangan Peredaran Narkotika Yang Terjadi Di Dalam Lembaga Pemasyarakatan Kelas I Palembang. Undergraduate Thesis, Sriwijaya University. http://repository.unsri.ac.id/id/eprint/36768

Bakhri, S., Aziz, A., \& Khulsum, U. (2019). “Analisis SWOT Untuk Strategi Pengembangan Home Industry Kue Gapit Sampurna Jaya Kabupaten Cirebon”. Dimasejati: Jurnal Pengabdian Kepada Masyarakat, 1(1), 64-81.

Baskoro, Wibowo (2021). Manajemen Pengamanan Dalam Menanggulangi Peredaran Narkoba Di Dalam Lembaga Pemasyarkatan Kelas Ii A Yogyakarta. Justitia : Jurnal Ilmu Hukum dan Humaniora. http://dx.doi.org/10.31604/justitia.v8i1.155-165

Creswell, J. W. (2019). Research Design: Pendekatan Kualitatif, Pendekatan Kuantitatif, dan Mixed (4th ed.). Yogyakarta: Pustaka Pelajar.

Helviza, Ira, Zulihar Mukmin dan Amirullah (2016). “Kendala-Kendala Badan NarkotikaNasional (bnn) Dalam Penanggulangan Penyalahgunaan Narkotika di Kota Banda Aceh, Jurnal Ilmiah Mahasiswa Pendidikan Kewarganegaraan Unsyiah Vol. 1, No. 1, url: https://media.neliti.com/media/publications/187604.

Khairunisa, Ravena (2021). Analisis Hambatan Pelaksanaan Eksekusi Pidana Mati pada Pelaku Tindak Pidana Peredaran Narkotika di Dalam Lembaga Pemasyarakatan Dihubungkan dengan Putusan Mahkamah Konstitusi Nomor 107/PUU-XIII/2015. Jurnal Riset Ilmu Hukum, https://doi.org/10.29313/.v0i0.7116

Nuraini, F. (2019). The Guide of SWOT. Yogyakarta: Quadrant.

Neuman, W. L. (2013). Metodologi Penelitian Sosial Pendekatan Kualitatif dan Kuantitatif (7th ed.). Jakarta: Indeks.

Payana, Widiati, Karma (2020). Penegakan Hukum terhadap Narapidana yang Melakukan Transaksi Narkotika di dalam Lembaga Pemasyarakatan. Jurnal Preferensi Hukum. https://doi.org/10.22225/jph.1.1.1988.80-85

Rejeki, Sri (2014). "Penanggulangan Narkoba Di Kalangan Remaja”, Majalah Ilmiah Pawiyatan, Vol: XXI, No: 1, url: http://download.portalgaruda.org/article.php.

Rafly (2020). Strategi Emergency Response Team (Ert) Terhadap Gangguan Keamanan . Justitia : Jurnal Ilmu Hukum dan Humaniora, (Hal 402-408).

Susetyo (2018). Penerapan Teori Keamanan Dalam Strategi Perancangan Lembaga Pemasyarakatan Dan Asimilasi Kelas I Di Tangerang. Senthong : Jurnal Ilmiah Mahasiswa Arsitektur, Vol 1 No 1.

Suryatama, E. (2014). Lebih Memahami Analisis SWOT dalam Bisnis. Surabaya: Kata Pena

Sahid (2021). Pengaruh Program Pesantren Terpadu Terhadap Mental Kepribadian Narapidana Di Lembaga Pemasyarakatan Kelas Iib Garut. Nusantara : Jurnal Ilmu Pengetahuan Sosial. 228-234.

Terkait, P., Sembiring, L. F., \& Maharani, U. (2019). ARBITER : Jurnal Ilmiah Magister Hukum and Order Disturbances at the Class IIb Correctional Institution. 1(2), 189-195.

Wulandari (2020). Pelatihan Kontrol Diri untuk Mencegah Relapse pada Narapidana Kelompok Rehab Mantan Pecandu Narkoba di Lapas. Jurnal Diversita. https://doi.org/10.31289/diversita.v6i2.4083

Yanarsya (2019). Strategi Penerapan Sistem Keamanan Pada Desain Lembaga Pemasyarakatan Kelas II Di Surakarta. Arsitektura : Jurnal Ilmiah Arsitektur dan Lingkungan Binaan. https://doi.org/10.20961/arst.v17i2.23508 